Irish Math. Soc. Bulletin

Number 71, Summer 2013, 5-11

ISSN 0791-5578

\title{
WHY WE NEED MATHEMATICS IN THE RPE ERA
}

\author{
RICHARD M. TIMONEY
}

\begin{abstract}
A thriving scientific eco-system at the national level in Ireland requires many kinds of interaction between many kinds of scientists, engineers, economic analysts and industry, and in this scenario Mathematics has a vital rôle to play. The $\mathrm{M}$ for Mathematics in the acronym STEM must include the new knowledge that comes from ongoing research.
\end{abstract}

\section{BACKGROUND}

The Research Prioritisation Steering Group which met between October 2010 and September 2011 has produced a series of recommendations that are now being implemented as part of national policy. In particular 14 themes have been identified in the report as priorities for public investment.

The report [1, Table 1] states that the underlying axioms (or high level criteria) used for the choices were as follows:

The Four High Level Criteria for Assessment of Priority Areas

(1) The priority area is associated with a large global market or markets in which Irish-based enterprise already compete or can realistically compete

(2) Publicly performed RED in Ireland is required to exploit the priority area and will complement private sector research and innovation in Ireland

(3) Ireland has built or is building (objectively measured) strengths in research disciplines relevant to the priority area

(4) The priority area represents an appropriate approach to a recognised national challenge and/or a global challenge to which Ireland should respond

Received on 26-6-2013.

This note has benefitted substantially from suggestions made by S. Buckley (NUIM), J. Carroll (DCU), J. Grannell (UCC) and P. Lynch (UCD).. 
For ease of reference, we list the priority areas in appendix A.

\section{The importance of Mathematics}

A recent UK report [3] (compiled for the EPSRC) is instructive in that it attempts to quantify (in accounting terms) the benefits accruing to the UK economy from Mathematics and graduates in Mathematics.

In that regard it acknowledges being influenced by a website [4] of the IMA (Institute of Mathematics and its Applications) which in turn identifies some mathematical applications that are already realised and some that are aspirations. Headings include "Fighting Infections with Symmetry" (priority area G), "Keeping Hearts Pumping" (priority area E), "Networking for the Future" (priority area A), "Taking decisions, not risks" and "Hydrogen: the fuel in water". Each of the (more than 30) headings is fleshed out in a two page flyer detailing the ideas behind the catchy titles, but we will not discuss them systematically here.

The report [3] comes up with a working definition of Mathematical Sciences Research (MSR), which is worth noting. Here is an abbreviated quote.

Mathematical science includes such diverse areas as algebra and analysis, dynamical systems, mathematical physics, operational research, probability and statistics: areas which touch on all aspects of everyday life.

For the purposes of this study we use the working definition of MSR as being high-end research in mathematical sciences carried out in academic institutions, research centres, businesses, individuals and Government that adds to the store of accumulated mathematical knowledge.

\section{Commentary}

The conclusions reached in [1] are broadly in line with ideas adopted in other countries and fundamentally fail to recognise the essential ingredient of inspiration provided by highly motivated individuals, and the long-established record of surprises.

The M of STEM is not explicitly treated in the report, despite its manifest involvement in almost all modern developments. The 
EPSRC in the UK does include Mathematics as a theme with the explanation

Research in the mathematical sciences is a key element for the advancement of all areas of science and technology, as well as being a vital area of science in itself. Our aim is to sustain core research capability, while promoting transformative and cross-disciplinary research that has the potential for significant impact.

(http://goo.gl/TDbzg or http://www.epsrc.ac.uk/ (May 2013).)

In the Irish context we have quite a few notable developments that were certainly not anticipated by many — for example John Boyd Dunlop and his commercialisation of the pneumatic tyre, Harry Ferguson of tractor and four-wheel drive fame, George Boole's logic (mid 19th century) which now pervades the digital era, William Rowan Hamilton's theories that now form the essential building blocks for many aspects of Physics and are used in computer games and graphics (see the successful Irish company Havok, www.havok. com, an Intel company now), and the large deviation theory which John T. Lewis used as the basis for the successful start-up Corvil (http://www.corvil.com/). The CTO and the Chief Scientist at Corvil hold PhDs in Mathematics. (The work of Corvil has a mathematical base and is included under priority areas A, B and N. The video games industry worldwide was valued at 65 billion US dollars in 2011, and at 248 million Euro in Ireland in 2012.)

Professor Arieh Iserles, a recent winner of the IMA-LMS David Crighton Medal, discusses (March 2013) the track record of predictions for technological advances over the past 60 years, comparing 1953 projections to 2013 reality, with striking lack of overlap between the lists. (See report at [2, p. 15].) First he discusses some examples including FFT (Fast Fourier Transform, Gauss 1805) and RSA encryption (named after a patent by Rivest, Shamir and Adelman in 1977), two further examples of the essential rôle of Mathematics. He uses these to argue against strategic choices, but says "a strategy for mathematics could be implemented at a higher level: research groups, departments/institutions and national/international levels".

He proceeds to guess that "the main driving force has shifted from physics to information over the past 50 years - the information age is here", something that would support the notion that Mathematics 
might be vital for items $\mathrm{A}, \mathrm{B}$ and $\mathrm{C}$ in the RPE list (see appendix A). In assertions that would perhaps make the late David Crighton, a computational fluid dynamicist who worked on aeroacoustics, rise from his grave in indignation, he is quoted as stating:

Information is the future and is a multidisciplinary mathematical enterprise, for example machine learning currently needs input from Approximation Theory, Bayesian Statistics, Computer Science, Functional Analysis, Graph Theory, Non-Parametric Statistics, Optimisation, Random Matrix Theory.

\section{Case studies}

As mentioned above, the web site [4] has quite a few well-documented examples of the importance of Mathematics in relation to recent and prospective developments.

In the Irish context, Peter Lynch (of UCD and formerly of Met Éireann) has written a series of short pieces aimed at the general public which are published in the Irish Times (fortnightly since July 2012) and he also has a blog [5] which contains links to his Irish Times articles.

For instance, his Irish Times column on March 7th 2013 was entitled X-ray vision: How CT scans changed medicine and discusses the mathematical basis for a CT scanner installed recently in Tallaght Hospital. In his blog (at http://thatsmaths.com/2013/ 03/07/ct-scans-and-the-radon-transform/) he goes into more mathematical detail and gives some recent bibliographic references. This is a topic where mathematical progress could well result in improved medical outcomes for patients from the next generation of scanners or from an update of their software. The particular topics to be addressed include clearer imaging via removal of artifacts (which might involve improved mathematical treatment of the raw data as well as changes to the design of the machine) and the possibility of lower power (resulting in lower exposure of patients to electromagnetic radiation) which can be expected to result from improvements in the underlying theory (but which would also be likely to involve hardware redesign). This should be included in priority areas $\mathrm{E}$ and $\mathrm{F}$.

The website [6] also discusses scanning (in an item headed How Math Can Save Your Life: Tomography by Dr. Chris Budd and 
Dr. Cathryn Mitchell; both are at the University of Bath, Budd is a mathematician and Mitchell an engineer).

While he was at Met Éireann, Peter Lynch was deeply involved in the development of HIRLAM (acronym for the High Resolution Limited Area Model), a Numerical Weather Prediction forecast system developed by an international group. This model involves physics, mathematics and computer programming techniques. It was especially necessary to improve forecasts for Ireland, a small area where the weather can vary dramatically over short distances, and HIRLAM works together with lower resolution European area forecasts to produce refinements that are useful here. The man in the street is easily convinced of the need for greater accuracy in forecasts and indeed there are economic benefits in accurate predictions of extreme events such as heavy snow or severe storms. Food production (involved in priority area I) can certainly benefit from accuracy in weather prediction, as could perhaps energy production (wind farms or marine energy - area $\mathrm{J}$ ), and there is certainly scope to continue to make improvements. A key goal is to be able to make long term projections with confidence, but there are mathematical no-go theorems which show that the current approach cannot be extended to forecasts beyond several days into the future. It is an area where new ideas could produce a revolutionary change.

Returning to medical devices (area E) the enhancement of cochlear implants is discussed at http://www. whydomath.org/node/hearing/WhatNext.html (retrieved May 2013, a page of [6]), where it is asserted that the limitations in terms of refined sound appreciation by patients cannot be overcome by physical design changes alone. Rather a call is made for mathematical progress.

In another direction, the possibility of viable quantum computers compromising the security of the widely used RSA-based cryptographic systems is a cause for concern. In [7] an approach is discussed where the complexity of solving number theoretic problems (at the heart of RSA) is replaced by more mathematically sophisticated ideas (concerned with abstract algebra and combinatorics). This approach seems to promise the benefit of being provably difficult to break and not easy for a hypothetical quantum computer, whereas the problem of factorisation of large numbers might be found to be less difficult than currently believed even without a 
quantum computer. One might speculate that a new version of the former publicly listed company Baltimore Technologies might emerge from research in this direction (covered under area B), perhaps even based in Ireland again.

In a nutshell then, Mathematics pervades modern life even though the public and policy-makers may not fully appreciate its place. The Mathematics that is and will be needed includes the very considerable body of mathematical knowledge, theory and technique that has already been developed and is an increasing challenge to convey to new generations. However it is also certain that new mathematical discoveries and insights will be vital for the near and more distant future. The sources [4] and [6] provide well-presented evidence of some aspects of the ubiquity of mathematics today, while the blog [5] provides a local Irish perspective.

\section{APPEndiX A. List OF THE PRIORITY AREAS}

A. Future Networks \& Communications

B. Data Analytics, Management, Security \& Privacy

C. Digital Platforms, Content \& Applications

D. Connected Health and Independent Living

E. Medical Devices

F. Diagnostics

G. Therapeutics: Synthesis, Formulation, Processing and Drug Delivery

H. Food for Health

I. Sustainable Food Production and Processing

J. Marine Renewable Energy

K. Smart Grids \& Smart Cities

L. Manufacturing Competitiveness

M. Processing Technologies and Novel Materials

N. Innovation in Services and Business Processes 


\section{REFERENCES}

[1] Report of the Research Prioritisation Steering Group - Department of Jobs, Enterprise and Innovation (2012) http://www.djei.ie/publications/ science/2012/research_prioritisation.pdf

[2] Report on the David Crighton Lectures and Medal Presentation 2013, London Mathematical Society Newsletter No. 425 (May 2013). http:// newsletter.lms.ac.uk/425/425.pdf

[3] Measuring the Economic Benefits of Mathematical Science Research in the $U K$, Report commissioned by the Engineering and Physical Sciences Research Council (EPSRC), November 2012, available at http://goo.gl/z4wNK

[4] Mathematics Matters, Website of the The Institute of Mathematics and its Applications (IMA), http://www.ima.org.uk/i_love_maths/ mathematics_matters.cfm (retrieved 16/5/2013)

[5] Peter Lynch, ThatsMaths, a Blog at http://thatsmaths.com/

[6] WhyDoMath, http://www.whydomath.org/index.html (retrieved $18 / 5 / 2013)$

[7] T. Güneysu, V. Lyubashevsky, and T. Pöppelmann, Practical Lattice-Based Cryptography: A Signature Scheme for Embedded Systems, in Cryptographic Hardware and Embedded Systems - CHES 2012, E. Prouff and P. Schaumont (Eds.), Lecture Notes in Computer Science 7428, 530-547, Springer 2012.

Richard Timoney is a Professor of Mathematics at TCD with research interests in complex and functional analysis, including operator algebras.

School of Mathematics, Trinity College Dublin

E-mail address: richardt@maths.tcd.ie 